\title{
O campo intelectual e de arte em Buenos Aires: debates e práticas artísticas*
}

\author{
Intellectual and art fields in Buenos Aires: \\ debates and artistic practices \\ Campo intelectual y de arte en Buenos Aires: \\ debates y prácticas artísticas
}

Maria Lúcia Bastos Kern**

Resumo: O presente artigo aborda a constituição do campo intelectual e de arte moderno em Buenos Aires, nos anos de 1920, quando a cidade passou por um intenso processo de modernização e se tornou um centro cosmopolita. A formação do campo de arte moderno se processou em contraposição às instituições do estado e aos intelectuais e artistas conservadores que mantinham as representações simbólicas nacionais limitadas ao meio rural e em apoio ao Estado oligárquico. O ensaio focaliza o "campo de forças", a sua fragmentação, as estratégias utilizadas pelos escritores e artistas e os debates suscitados pela modernidade estética, bem como as emblemáticas produções culturais permeadas pelas tradições nacionais, poéticas modernas e pela arte social.

Palavras-chave: tradição, modernidade e identidade nacional

Abstract: This article analyses the constitution of the intellectual field and modern art in Buenos Aires, in the 1920s, when the city went through an intense process of modernization and became a cosmopolitan center. The formation of the modern art field is processed as opposed to state institutions and conservative intellectuals and artists

\footnotetext{
* Artigo resultante de parte do projeto de pesquisa Modernidade no Brasil e países platinos desenvolvido com apoio da bolsa PQ do Conselho Nacional de Desenvolvimento Científico e Tecnológico (CNPq).

** Doutora em História da Arte - Université de Paris I (Pantheon-Sorbonne) com pós-doutorado pela Université de Paris I e pela École des Hautes Études en Sciences Sociales. Atualmente é professora titular da Pontifícia Universidade Católica do Rio Grande do Sul, do Programa de Pós-Graduação em História, Pesquisador 1 A do CNPq, Pesquisadora Associada do EFISAL Equipe Fonctios Imaginaires et Sociales des Arts et des Littératures, da EHESS. Tem experiência na área de Artes, com ênfase em História e Teoria da Arte. É autora de vários estudos, dentre os quais destaca-se Arte Argentina: Tradição e Modernidade (EdiPUCRS, 1996). <mikern@pucrs.br>.

PhD. in Art History - Université de Paris I (Pantheon-Sorbonne) with postdoctoral researches developed at the Université de Paris I and École des Hautes Études en Sciences Sociales. She is full professor at the Pontifícia Universidade Católica do Rio Grande do Sul (PUCRS), History Department. CNPq Ressearcher 1 A and Associate Researcher of EFISAL - Equipe Fonctios Imaginaires et Sociales des Arts et des Littératures, at EHESS. Her main themes are Arts, Art History and Theory. She is the author of Arte Argentina: Tradição e Modernidade (EdiPUCRS, 1996).<mikern@pucrs.br>.
} 
who maintained national symbolic representations limited to rural areas and in support of the oligarchic state. This paper focuses on the "force field", its fragmentation, the strategies used by writers and artists, and the debates raised by aesthetic modernity as well as the flagship cultural productions permeated by national traditions, modern poetry and social art.

Keywords: tradition, modernity and national identity

Resumen: Este artículo tiene como objetivo la constitución del campo intelectual y del arte moderna en Buenos Aires, en la década de 1920, cuando la ciudad pasó por un intenso proceso de modernización y se convirtió en un centro cosmopolita. La formación del campo del arte moderna se procesa en oposición a las instituciones del Estado y los intelectuales y artistas conservadores que mantienen representaciones simbólicas nacionales limitados a las zonas rurales y apoyar el estado oligárquico. Este artículo se centra en el "campo de fuerza", su fragmentación, las estrategias utilizadas por los escritores y artistas y los debates planteados por la modernidad estética, así como las producciones culturales emblemáticas permeadas por las tradiciones nacionales, la poesía moderna y el arte social.

Palabras clave: tradición, modernidad y nacional de identidad

\section{Introdução}

As primeiras décadas do século XX, em Buenos Aires, peculiarizaram-se pelo intenso debate intelectual a respeito do nacionalismo, do cosmopolitismo e da arte moderna diante do processo de modernização da Argentina e das rápidas transformações sociais e culturais resultantes da imigração, da recente industrialização e do crescimento econômico. Esse debate ocorreu através de novos periódicos, os quais criaram espaços para difundir distintas concepções relativas às atividades culturais e aos movimentos de vanguarda internacionais, porém sem deixar de refletir a respeito da cultura nacional e das ideias de nação. Muitos dos periódicos representavam ideologias de diferentes grupos de intelectuais, instituições e estratégias de intervenção política; outros estabeleceram programas com vistas à educação do público e ao estabelecimento do campo de arte moderno e de reformas sociais. A crítica de arte também exerceu papel extremamente importante para a formação de gosto do público, de conceitos de arte moderna e para a constituição de coleções e de mercado consumidor. A partir do conceito de campo de Pierre Bourdieu busca-se analisar o campo de arte como "campo de forças", nos quais os agentes traçam estratégias para a consagração de distintas acepções de arte moderna e de identidade nacional, sem se restringir ao mero conflito entre tradição e modernidade. Ao se considerar esse cenário de múltiplas concepções, de embates simbólicos e de divergências, destaca-se que o enfoque desse artigo se 
centraliza no artista Xul Solar (1887-1963), que juntamente com outros artistas e escritores, atuou como protagonista para a institucionalização da arte moderna em Buenos Aires, ao estabelecer estratégias para a sua divulgação e formação de público.

\section{Xul Solar e a emergência do campo intelectual e artístico}

Em 1912, Xul Solar viajou para a Europa para dar continuidade a sua formação artística e entrar em contato com os movimentos de vanguarda. Para tal residiu de forma temporária em várias cidades, como Paris, Turim, Florença, Milão, Berlim e Munique, onde conheceu novas concepções e práticas artísticas, como o Expressionismo, o Cubismo, o Futurismo e a arte abstrata, que possibilitaram a Xul a criação de nova poética e a distinção de sua pintura em relação àquelas produzidas pelos colegas argentinos.

Em Buenos Aires o ambiente artístico era dominado por obras condicionadas à temática nacional, as quais exaltavam a paisagem da região do Pampa e o tipo social do gaúcho em suas atividades campeiras, como se pode verificar nas pinturas de artistas do grupo Nexus (1907-10), como Carlos Ripamonte, Cesáreo Quirós e Fernando Fader, dentre outros $^{1}$ (PEREZ, 2010, p. 32) (BURUCUA, J. E.; TELESCA, s/d, p. 89-90). Nos anos de 1910 e 20, as instituições de arte oficiais também estimulavam as representações visuais vinculadas aos signos nacionais, na busca de glorificação do gaúcho e de suas práticas culturais. No entanto, durante a Exposição Internacional de Arte do Centenário (1910), em comemoração à Independência, alguns artistas exprimiram a sua consciência de que não existia na Argentina arte nacional, apesar dessas representações. Estas manifestações não tiveram alcance junto ao Estado, que concedeu o grande prêmio a Quirós pela série de pinturas

\footnotetext{
${ }^{1}$ A presença do nacionalismo na arte e nos debates entre os intelectuais foi decorrente do temor de desintegração social resultante do processo de modernização, da entrada de grande contingente de imigrantes europeus, de 1891 a 1914, e do consequente crescimento vertiginoso da população e do espaço urbano. Em Buenos Aires $75 \%$ da população era composta por imigrantes europeus alfabetizados que representavam um promissor mercado de consumo cultural. Os estrangeiros ao buscarem a igualdade e a inserção social, fizeram uma série de reivindicações políticas e greves, que geraram frequentes conflitos sociais. Estas tensões também se fizeram presentes no campo de arte. Em 1903, o artista Martín Malharro tinha consciência da necessidade de criar arte nacional, mas acreditava que esta não precisaria se constituir numa representação de cena criolla. Malharro manifestou que "Para fundamentar a pintura nacional, é necessário que esqueçamos quase, o que aprendemos nas escolas europeias. É preciso que frente a frente à natureza de nosso país, indagarmos seus mistérios, explorando, buscando o signo e o meio apropriado para sua interpretação (...)". Para ele, era a luz, a cor e a sensibilidade do artista é que permitiriam conduzir à arte autêntica argentina.
} 
que retratavam o gaúcho. Nelas haviam pinceladas densas, coloridas e luminosas que remetiam a remanescentes do Impressionismo francês, muito apreciado pelo público.

O campo de arte em Buenos Aires encontrava-se no início do século estruturado em instituições do Estado: o Museu (1895), a Academia (1905) e o Salão Nacional de Belas Artes (1911), comprometidas com o estímulo à arte argentina e às representações simbólicas do campo.

Com os festejos do Centenário ${ }^{2} \mathrm{e}$ as mudanças sociais, econômicas ${ }^{3}$ e culturais, decorrentes dos processos de imigração e modernização da Argentina, a cidade de Buenos Aires, centro de acentuada expansão cultural, tornou-se cosmopolita e o nacionalismo se acentuou, sobretudo, entre os líderes políticos e intelectuais oriundos do meio rural e das províncias. $\mathrm{O}$ otimismo resultante das previsões de progresso não perdurou muito, diante do impacto imigratório e dos conflitos sociais e políticos resultantes ${ }^{4}$. (BARBERO, DEVOTO, 1983, p. 16-17). A comemoração da Independência ensejou discursos fundados nas tradições culturais argentinas em busca da coesão social frente às divergências ideológicas e ao temor de que a forte presença estrangeira conduzisse ao processo de dissolução da nação.

$\mathrm{Na}$ literatura, muitos escritores compartilhavam ideais nacionalistas, fundamentados no espiritualismo e no Modernismo de Rubén Darío. O apoio oficial à literatura e às pinturas relativas às tradições rurais e populares das províncias foi decorrente, em parte, da ocupação por intelectuais nacionalistas de importantes cargos dirigentes junto ao Estado. Esses intelectuais estimularam o debate ideológico, a partir de revistas e livros 5 , que se constituíram, desde o final do século XIX,

\footnotetext{
${ }^{2}$ Durante os festejos da independência política do país foi organizada uma grande Exposição Internacional de Arte, da qual participaram dezoito nações. A França remeteu 480 obras de artistas do Impressionismo, Simbolismo e de movimentos do início do século XX. A Espanha compareceu com 300 obras de artistas nacionalistas e do Modernismo.

${ }^{3}$ A expansão econômica era resultante do estabelecimento de frigoríficos que exportavam a carne de gado, do comércio e da industrialização.

${ }^{4}$ A crise ampliou com os conflitos sociais liderados pelas organizações operárias, formadas em grande parte por imigrantes, anarquistas e socialistas que reivindicavam maior participação política nas decisões nacionais e melhores condições de trabalho.

${ }^{5}$ Dentre os escritores destacavam-se: Ricardo Rojas, Leopoldo Lugones e Manuel Gálvez. O primeiro foi reitor da Universidade de Buenos Aires (1926-30), durante o governo de Hypólito Yrigoyen (1916-1922; 1928-30) e extremamente respeitado por seus livros e textos em jornais, como La Nación. Lugones, de família de grandes proprietários rurais, inicialmente defendeu ideias socialistas e escreveu no jornal La Vanguardia. Ao absorver as concepções espirituais de Rubén Darío, as divulgou em matérias no jornal La Nación. Recebeu prêmios literários (1926), e presidiu a Sociedade Argentina de Escritores (1928). Manuel Gálvez foi membro da Academia Argentina de Letras, da Real Academia de Espanha (1928) e indicado três vezes para o Prêmio Nobel de Literatura, em 1933, 1934 e 1951. Atuou como crítico de arte em prol do nacionalismo.
} 
nos veículos utilizados para pensarem a nação, se promoverem como profissionais e colaborarem ativamente nas políticas culturais e institucionais do país.

Muitos desses intelectuais atuaram como gestores do nacionalismo argentino, sendo que alguns na busca de preservação do modelo oligárquico, que já evidenciava o seu esgotamento, enquanto outros foram conduzidos diante das mudanças sociais a assumirem ideais do socialismo e anarquismo e a liderarem a projeção de reformas do Estado. Os intelectuais vindos das províncias e detentores de menor poder junto às elites políticas e econômicas, programaram o renascer da cultura nacional a partir de certo anticosmopolitismo e de aportes espiritualistas. Esses intelectuais preocuparam-se ainda com a profissionalização do escritor diante do capital educacional da população estrangeira na cidade, sobretudo dos setores médios, e incentivaram a constituição de um campo literário e artístico que estimulasse a cultura nacional, que acreditavam ser necessária e urgente para a existência da nação.

O cosmopolitismo ${ }^{6}$ acentuou o nacionalismo, porém destituído de um caráter unitário, visto que alguns intelectuais defendiam as tradições hispânicas e das províncias argentinas, outros as memórias rurais, americanas e as tradições criollas, de origem espanhola e indígena. Os gêneros da paisagem e dos tipos sociais regionais foram consagrados pela crítica de arte e objeto de militância por Manuel Galvez (1912-14), a partir da revista Nosotros (1907-43), para formar a opinião pública ${ }^{7}$ (MUÑOZ, 2012, s/p.). Ele exerceu a militância estético-ideológica através de instâncias institucionais, como os Salões, na defesa da arte que fosse verdadeira e expressasse a alma e o caráter do argentino $^{8}$.

O escritor Ricardo Rojas (1888-1957)9 , desde a publicação de La restauración nacionalista (1910), propunha de forma recorrente a necessidade de dotar a população de uma "consciência histórica", para

\footnotetext{
${ }^{6}$ Desde o final do século XIX, quando Torcuato de Alvear assumiu o cargo de primeiro intendente de Buenos Aires, o seu objetivo era transformar a cidade em uma metrópole cosmopolita europeia. Rojas sofreu grande impacto cultural quando saiu de Santiago del Estero e chegou a Buenos Aires, devido ao seu cosmopolitismo e à acentuada presença de população estrangeira $(75 \%)$. Ele propagou através do jornal Las Nación a ideia de renascimento nacional e o aporte da herança hispano-americana, segundo uma visão espiritualista.

${ }^{7}$ Nosotros era uma revista mensal de Letras, Arte, História, Filosofia e Ciências Sociais. Foi dirigida por Alfredo Bianchi e Roberto Giusti e tinha a meta de delimitação do campo intelectual argentino e de difusão de escritores locais, da América Latina e da Espanha.

${ }^{8}$ A questão central para os intelectuais nacionalistas era salvar a nação da ameaça do cosmopolitismo e dos conflitos sociais presentes nas manifestações operárias.

${ }^{9}$ Rojas viajou pela Europa, com apoio do estado argentino, para conhecer os sistemas de educação de cada país.
} 
homogeneizar a educação do país e reduzir as diferenças culturais. $\mathrm{O}$ seu projeto de reforma educacional tinha a história como disciplina central, e foi posteriormente implementado pelo Estado, tendo a meta de ampliar a formação dos imigrantes segundo princípios e valores fundados nas tradições espiritual e nacional. A escola era concebida como o instrumento mais eficaz de nacionalização, disciplina e homogeneização. Rojas, em oposição ao Estado autoritário oligárquico, propôs a instituição do voto, reivindicado pelos imigrantes e pela classe operária. As suas proposições de reforma foram implementadas e deram origem ao nacionalismo democrático e laico. (PULFER 2010, p. 20-21) Ele verificou que não seria o caso de atacar a modernização, mas de integrar o aporte estrangeiro ao desenvolvimento nacional. Esta projeção permitiria também a criação de uma cultura própria, na qual o domínio da linguagem castelhana seria fundamental.

Já os escritores Leopoldo Lugones (1874-1938) e Manuel Gálvez (1882-1962) temiam a ameaça da idiossincrasia cultural pela pressão linguística, cultural e ideológica do imigrante. Esses escritores propalaram a "reação nacionalista" diante da crise social vivenciada e fomentaram o legado hispânico. Lugones ${ }^{10}$ (ROMERO, 1987, p. 150) e Gálvez $^{11}$, detentores de pensamento mais conservador, radicalizaram ao projetarem o mito da raça sem mescla para evitar a degradação cultural. O primeiro defendia a necessidade de incentivar o patriotismo para que o argentino não se sentisse estrangeiro no seu próprio país.

Durante a década de 1920 eles continuaram resistindo às novas práticas artísticas e consagrando a pintura herdada do Impressionismo, presa às representações das tradições rurais. A crítica de arte instituída defendia a preservação dessas representações e acusava os jovens artistas de "imitadores dos europeus" que estavam "em moda" e tinham "como preocupação primordial, a receita alheia" (WECHSLER, 1989a, p. 43). Já o discurso de Rojas não era resultante apenas de uma conduta de resistência ao moderno, mas de intranquilidade diante da

\footnotetext{
${ }^{10}$ Leopoldo Lugones exaltou as tradições criollas e o mito do gaúcho, desde a conferência, intitulada El Payador (1906), bem como a formação espiritual nacional em oposição aos imigrantes e mestiços. Simpatizou com o fascismo e apoiou, em 1930, o golpe militar de José Felix Uriburu (1930-32). O nacionalismo atingiu o auge em 1913, quando os poemas de Hernández foram concebidos como fundadores da nacionalidade, sendo os mesmos acompanhados pela oposição à industrialização, motivada pelos movimentos operários. A pureza linguística foi valorizada por Lugones, ao analisar a obra de José Hernández Martín Fierro, e por escritores do Centenário.

${ }^{11}$ Manuel Gálvez, escritor católico e nacionalista, assumiu como Lugones posicionamento anticosmopolita e anti-liberal e tornou-se admirador do fascismo. Em El diário de Gabriel Quiroga. Opiniones de la vida argentina (1910), ele revelou o temor à modernização e à degradação dos costumes.
} 
pluralidade, das tensões sociais e culturais geradas pela imigração e pelo cosmopolitismo. O escritor temia que a introdução de ideias, valores e costumes estrangeiros levasse à dissolução dos ideais de nação, das tradições argentinas e de coesão social (ROMERO, 1994, p. 27). Rojas defendeu como solução, integrar as populações nativas gaúcha, criolla, com os imigrantes.

Em Eurindia. Ensayo de estética fundado en la experiência histórica de las culturas americanas (1924), Rojas propôs uma estética regida por leis que permitissem dar continuidade à tradição, para que na Argentina não se perdesse a memória coletiva e a identidade nacional. Para ele, a tradição simbolizava a unidade e a autonomia do espírito (WECHSLER, 1989b, p. 91-99). Essa não deveria renegar a herança da cultura europeia e nem da indígena. Esse ensaio teve grande repercussão no país, durante duas décadas, sendo referência para artistas e arquitetos. Rojas acreditava que a arte era o meio de formar a consciência nacional e educar a população ${ }^{12}$ (PENHOS, 1999, p. 113). Como ele, a crítica de arte concebia que a consciência nacional se fundava nas singularidades do território, nas suas formas, e na memória coletiva que permitiria o sentimento histórico comum. Com isto, a crítica de arte oficial assumiu uma posição contrária às vanguardas, ao negar ou ignorar as obras emblemáticas de Xul Solar, Emilio Pettoruti, Raquel Forner, Horacio Butler, Victor Pissarro e Juan Del Prete. Eles foram considerados como uma ameaça à ordem estabelecida, por transgredirem aos pressupostos estéticos oficiais ${ }^{13}$ (WECHSLER, 1989b, p. 101).

Em Eurindia, o discurso de Rojas também salientava a necessidade de conciliar a técnica europeia com a emoção americana, para construção da autonomia cultural. Rojas achava que esta era a missão que a arte deveria desempenhar naquele momento.

\footnotetext{
${ }^{12}$ A literatura argentina desse momento considerava o imigrante trabalhador, mas inculto e sem projetos elevados.

${ }^{13}$ A autora fez um levantamento das obras premiadas e verificou que predominavam os temas do campo e da paisagem do território argentino.1921-112 pinturas: 52 paisagens, 9 retratos, 3 nus, 3 animais, 28 outros.

1924-117 pinturas: 54 paisagens, 11 retratos, 6 nus, 2 animais, 4 naturezas-mortas, 30 outros.1928-254 pinturas: 83 paisagens, 24 retratos, 12 nus, 17 naturezas-mortas, 54 outros. Os primeiros prêmios entre 1920/30 foram distribuídos da seguinte forma: 4 paisagens, 2 retratos, 1 animal, 2 nus e 1 cena de trabalho. Os dados denotam o crescimento do número de pinturas expostas e o domínio da paisagem. A partir de 1924, aparece a natureza-morta e há o aumento de nus, temas propícios para a exploração plástica e libertação do fim narrativo da pintura. A paisagem também seria o meio para novas pequisas, se esta não tivesse impregnada pela doutrina nacionalista.
} 
Anos antes, o arquiteto Angelo Guido apresentou no Salão Nacional (1920) um projeto intitulado, "Ensaio em direção a um Renascimento Colonial" e depois, em 1924, defendeu as ideias de Rojas em prol da fusão do europeu e do indígena como primeiro passo para "nossa estética americanista verdadeira" e para a criação de uma "arte nacional e americana". Entretanto, esta arte não seria nem europeia e nem indígena (exótica e primitiva), pois deveria a última passar pelo filtro colonial para conformar a fusão (GUIDO, 2003, p. 37). No ano seguinte Guido publicou Fusión hispano-indigena en la arquitectura colonial (1925), na qual propôs a arte que conciliasse o nacional e o americano, sendo a mesma aceita por numerosos intelectuais, por acreditarem que permitiria a constituição da identidade cultura ${ }^{14}$ (LOPEZ ANAYA, 2005, p. 172). Guido resgatou a cultura incaica nos elementos decorativos $\mathrm{e}$ os conciliou com a arquitetura hispânica. Rojas criou poesias nas quais retomou a temática incaica, no momento em que a arqueologia permitia o melhor conhecimento dessa cultura.

A síntese entre o europeu e o americano já vinha sendo perseguida por Xul Solar, antes de retornar da Europa (1924), em texto e ao resgatar as tradições pré-colombianas em suas pinturas, tais como: Nuevo Mundo (1919), América, Tlaloc (1923) e, posteriormente, Drago e Outro Drago (1927). Estas pinturas revelam que o seu enfoque antecedeu às questões debatidas por Rojas e Guido. Xul tinha como meta a unidade americana e a retomada dos mitos e símbolos pré-colombianos. Em texto escrito por ocasião da mostra de Emilio Pettoruti em Berlim, na galeria Der Sturm, de Herwarth Walden (1923), Xul declarou:

Somos e nos sentimos novos, à nossa meta nova não conduzem caminhos velhos e alheios. Diferenciemo-nos. Somos maiores de idade e ainda não terminamos as guerras pró-independência. Acabe já a tutela moral da Europa. (...). Amemos nossos mestres, mas não queiramos mais nossas únicas Mecas em ultramar (ARTUNDO, 2005, p. 26).

Em tom de manifesto ele registrou a sua intenção de revolucionar a arte no seu país e fazer desta o modelo para Europa, bem como projetou a unidade da América através de nova língua comum, o neocriollo, fruto da junção do espanhol e do português ${ }^{15}$. A unidade americana

\footnotetext{
${ }^{14}$ Guido projetou a casa de Rojas (1923) segundo estilo hispano com decoração incaica.

${ }^{15} \mathrm{O}$ neocriollo, língua criada por Xul que consistia na integração do espanhol e do português falado no Brasil. Consciente de que o neocriollo era numa língua eurocêntrica, introduziu mais tarde o inglês, o alemão e por último o guarani, para contemplar os povos indígenas da América.
} 
se processaria também por meio das artes e da espiritualidade. Xul acreditava que era necessário "ao mundo cansado, acrescentar sentido novo, uma vida mais múltipla e mais alta nossa missão de raça que se alça. (...) Pois somos uma raça esteta, (...) começaremos a dizer o nosso novo" (ARTUNDO, 2005, p. 26).

As mudanças de concepções de arte iniciaram antes na capital portenha com a vinda de intelectuais espanhóis, como José Ortega y Gasset (1916) e Eugênio D’Ors (1916 e 1921), que estimularam o interesse pela cultura hispânica, após um momento de intensa oposição ao colonizador ${ }^{16}$. A noção de nova sensibilidade, difundida em conferências por Gasset, foi amplamente discutida e aplicada nos discursos dos escritores e artistas que buscavam a modernidade estética, assim como a noção de cultura laica. Já D’Ors, escritor que liderou o Novecentismo em Barcelona, demonstrou a relação da tradição com a modernidade e o sucesso do projeto de construção de cultura própria para Catalunha ${ }^{17}$ (KERN, 2014, p. 857-858) (D'ORS, 2000, p. 60-62). As duas orientações exerceram efeitos sob a arte argentina e o meio intelectual jovem.

Outras concepçõesemergiram nas décadas de 1910 e 1920 com os artistas oriundos das classes operárias que constituíram a Escuela Barracas, e se manifestaram contra a Academia Nacional de Bellas Artes e o sistema hegemônico de legitimação da arte que esta instituição e $o$ Salón de Bellas Artes exerciam. O grupo praticava muito a gravura, além de pintura que, em geral, eram conectadas com o realismo social. Esses artistas conhecidos como Artistas del Pueblo, de filiação anarquista, criaram o Salón de Rechazados (1914), o Salón de Independientes, sem júri e sem prêmios (1918) e a revista Ideas y

As invenções linguísticas eram constantes, fato que apenas o seu criador tinha domínio do neocriollo. Assim, a sua meta de língua para a América não se concretizou.

${ }^{16} \mathrm{O}$ interesse pela cultura hispânica era de tal ordem que levou à criação de uma cátedra na Universidade de Buenos Aires.

${ }^{17}$ A partir de 1906, em Barcelona, D’Ors liderou o projeto de modernização da Catalunha, o Novecentismo, que se baseava no retorno às raízes mediterrânicas. Por meio de seu "Glosari", coluna publicada no periódico "La Veu de Catalunya", desde 1906, e dos livros Almanac dels noucentistes e La Ben Plantada (1911) D’Ors difundiu os aportes teóricos da "nova" estética para a Catalunha. Ele considerava que a arte, como a expressão coletiva, poderia exercer o papel ético, cívico, construtivo e preparar o futuro da sociedade catalã. O projeto tinha em vista a construção de nova ordem social, em oposição às decadentes manifestações do Modernismo e do Simbolismo, rejeitados pelos seus excessos ornamentais, pelo individualismo e internacionalismo que provocaram na cultura da Catalunha, além de seus vínculos com valores espirituais da Idade Média. D’Ors propagou o Novecentismo na Argentina, para constituir novas gerações de intelectuais, em contraposição ao positivismo e ao materialismo. A partir de suas estadias em 1916 e de suas conferências, alguns intelectuais egressos da Faculdade de Filosofia e Letras criaram o Colégio Novecentista (1917) para estimular o movimento renovador. 
Figuras (1912) ${ }^{18}$ (MUÑOZ, 1994, p. 23-26). Nesta publicação, Alfredo Chiabra inaugurou a seção de artes plásticas, na qual ele assinava com pseudônimo de Atalaya, e começou a se projetar como crítico de arte respeitável e a atuar em vários periódicos até 1932. Ele não aceitava a arte limitada às inovações europeias, defendia a arte direcionada ao povo e incentivava a representação da paisagem nacional. Outro grupo formado por artistas e escritores oriundos do Partido Comunista e defensores do realismo social foi Boedo, que surgiu a partir da revista Pensadores (1922-26) a qual teve continuidade com a revista Claridad (1926-41), e promoveu o debate e a oposição aos escritores e artistas que militavam pela difusão da modernidade ${ }^{19}$.

$\mathrm{O}$ acentuado nacionalismo no âmbito cultural não limitou a entrada no país de notícias sobre os movimentos de vanguarda europeus. $\mathrm{O}$ primeiro Manifesto Futurista (1909) de Filippo Marinetti, foi traduzido do francês para o castelhano por Rubén Dario, e publicado no jornal La Nación um mês após a divulgação do texto no jornal Le Figaro. A revista futurista Rovente (1924), dirigida pelo italiano Piero Illari e com a colaboração de Sandro Piantadina e Sandro Volta, circulou em Buenos Aires, com texto de Marinetti e fotografias das obras de Giacomo Balla dentre outros ${ }^{20}$ (ALCALÁ, 2009, p. 17). No entanto, nesse momento o contato com as vanguardas europeias era restrito e o futurismo não chegou a formar seguidores em Buenos Aires. Circulou também a revista Ocidente (1923-36), criada na Espanha e dirigida por José Ortega y Gasset, com informações sobre os movimentos artísticos modernos. Essa revista tinha ampla circulação internacional na Europa e América Latina, era multidisciplinar e exerceu grande impacto em meio às vanguardas.

O crescimento econômico e numérico de artistas formados propiciou o aumento de bolsistas do estado no exterior, que nos anos de 1910 e 20 se dirigiam à Itália, à França, à Espanha e à Alemanha ${ }^{21}$. Os contatos dos

\footnotetext{
${ }^{18}$ Em 1914, a Escuela Barracas foi denominada de Artistas del Pueblo e criou a primeira agremiação anárquica na Argentina, a Sociedad Nacional de Pintores y Escultores (1916) e o Salón Nacional de Artistas (1918), denominado de Indepiendientes, sem juri e premiação.

${ }^{19} \mathrm{O}$ debate aconteceu entre Boedo e o grupo da revista Martín Fierro, que ficou conhecido como "Boedo e Florida" devido às suas localizações nas calles Boedo e Florida. O editorial Claridad publicou livros populares e baratos de grande divulgação e colaborou na constituição de um nicho forte de consumo.

${ }^{20}$ Manifesto em francês foi publicado em 20 de fevereiro de 1909 e em castelhano em 21 de março do mesmo ano. As revistas estrangeiras que circulam entre os artistas argentinos trazem informações sobre outras as artes de vanguarda, como Der Sturm, De Stijl etc.

${ }^{21}$ Horacio Butler, Lino Spilimbergo, Hector Basaldúa, Aquiles Badi, Antonio Berni, Raquel Forner, Del Prete. Outros artistas foram para o exterior sem bolsa, tais como Norah Borges, Emilio Pettoruti, Xul Solar etc.
} 
artistas com as inovações plásticas permitiram a absorção de distintas concepções e práticas artísticas e, consequentemente, de tensões no interior do campo, formado por instituições do estado relativamente conservadoras. Os jovens artistas procuraram novas estratégias para fortalecer as suas posições, legitimá-las e difundi-las ao grande público. Eles criaram revistas e entidades privadas que auxiliaram no progressivo processo de profissionalização e estabeleceram normas específicas que possibilitassem certa autonomia da arte e do campo artístico. No entanto, esse programa em prol da renovação foi seguido por avanços e recuos.

Outra iniciativa importante foi a de Jorge Luis Borges, quando retornou da Espanha (1920) e criou o periódico em forma de cartaz, Prisma (1921-22), no qual divulgou o Ultraísmo e sua irmã Norah fez as ilustrações. Os dois irmãos haviam participado do movimento Ultraísta na Espanha, onde praticavam uma poética de caráter expressionista, sendo que Norah imprimiu em seus desenhos e pinturas um sentido lírico 22 (KERN, 1996, p. 125-139). As distintas poéticas do Ultraísmo - de teor expressionista e futurista - difundiram-se rapidamente entre os artistas portenhos e se fundamentaram, sobretudo, nas formas construídas e dinâmicas. O grupo, que se formou em torno do movimento, se apresentava como "escola de vanguarda" e foi reconhecido como tal pela revista Nosotros que começou a publicar textos de Borges e o manifesto do Ultraísmo. A revista Proa (1922-23) foi também criada para a divulgação das novas poéticas, bem como o periódico Atlántida (1923-24) que deu destaque aos artigos de Julio de La Paz, nos quais o autor preparou o público e a crítica para explicar o Ultraísmo literário e o Futurismo ${ }^{23}$ (ARTUNDO, 1997, p. 16). Outras manifestações individuais foram efetuadas, como por exemplo, o escritor Eduardo González Lanuza assumiu em texto (1921) a sua posição futurista e justificou que a sua acepção não era a

\footnotetext{
${ }^{22}$ O Ultraísmo se constituiu como primeiro movimento literário e artístico de vanguarda na Espanha que se opunha aos regionalismos e nacionalismos. Foi criado em Sevilha em 1919 e se difundiu no ano seguinte em Madri, a partir de vertentes distintas: uma apoiada no Expressionismo alemão do pós-guerra, outras no Futurismo italiano, no Creacionismo e no Construtivismo da poesia francesa. Ultra significava o sentido dinâmico que deveria identificar a nova arte. A revista Ultra era o espaço no qual os artistas produziam suas experiências, buscando a renovação, sem fins unitários. As formas esquematizadas e construídas eram trabalhadas na poesia e nas artes visuais com o fim de atingir a sua pureza. Jorge e Norah Borges introduziram na Espanha a lírica expressionista, após estadia na Suíça (1914-18) e, depois, em Buenos Aires.

${ }^{23}$ A revista Nosotros era o principal periódico da geração de intelectuais do Centenário. Em dezembro de 1921, ela publicou o mencionado manifesto. O jornal La Nación anunciou o livro de Alberto Candiotti, Pettoruti:"futurismo, cubismo, expressionismo, sintetismo, dadaísmo, publicado (1923) pela editora Internacional de Berlim e Buenos Aires.
} 
mesma defendida por Filippo Marinetti, mas contra a cristalização do passado $^{24}$ (PEREZ, 2010, p. 41).

Em 1924, foi fundada a Associación de los Amigos del Arte, que reunia artistas e escritores com o objetivo de promover conferências, concertos e exposições, bem como a reflexão sobre a estética da modernidade. Essa associação, ao mesmo tempo, que promoveu palestras de Filippo Marinetti, Le Corbusier, Guillermo de Torre e intelectuais argentinos, exposições de artistas modernos, franceses, alemães e locais, também apresentou em seus salões obras de artistas oficiais nacionalistas, como por exemplo, as pinturas de Fernando Fader. Amigos del Arte possibilitou ainda aos intelectuais europeus difundirem as ideias norteadoras das artes contemporâneas ${ }^{25}$.

Nesse mesmo ano apareceu a revista quinzenal Martín Fierro (1924-1927) ${ }^{26}$, cujo nome fazia alusão à obra literária de Hernández ${ }^{27}$. Ela tinha a meta de estabelecer um projeto de renovação estética e de integração das atividades dispersas dos novos escritores, artistas e arquitetos para dar certa unidade ao movimento moderno a ser implantado. Os colaboradores, oriundos inicialmente do Ultraísmo, assumiram a função de militância em prol das novas práticas artísticas e de sua difusão. No manifesto publicado no quarto número da revista, os escritores e artistas reagiram "frente à ridícula necessidade de fundamentar nosso nacionalismo intelectual, inflando valores falsos (...)" e salientaram que estavam diante de "uma Nova Sensibilidade" e da descoberta de "novos meios e formas de expressão" (Martín Fierro, 1924, p. 23). Para sustentar o seu projeto de renovação, Martín Fierro apoiou-se na revisão da tradição nacional e no cosmopolitismo para assim construir a nova identidade nacional circunscrita ao meio urbano. Os seus mentores buscaram promover a unidade em face à diversidade étnica e cultural, que compunha a moderna sociedade argentina e tentaram solucionar desta forma os conflitos sociais

\footnotetext{
${ }^{24}$ Ramón Gómez Cornet expõe em 1921, na Galeria Chandier, em Buenos Aires após estudos e mostras em Barcelona e Paris. Sua pintura evidencia o contato com obras de Cézanne e de artistas cubistas, porém sem abandonar a figuração e os temas nacionais. As exposições de Emílio Pettoruti (1924) e Curatela Manes provocaram um impacto no público diante de suas novas poéticas, desconhecidas em Buenos Aires.

${ }^{25}$ Em 1926, Marinetti esteve no Brasil e na Argentina e Salas Subirat publicou Marinetti. Un ensayo para los fósiles de lo futurismo. Buenos Aires: Editorial Tor, 1926.

${ }^{26}$ A revista era dirigida por Evar Méndez e compunha a redação: Borges, González Lanuza, Oliverio Girondo, Leopoldo Marechal, Francisco Luiz Bernárdez, Cyetano Córdova Itruburu, Nicolas Olivari, Xul Solar, Norah Lange, Pablo Rojas Paz,Horacio Rega Molina, Brandán Caraffa dentre outros.

${ }^{27} \mathrm{O}$ nome da revista veio de sua primeira versão, quando foi criada em 1919 com objetivos políticos.
} 
gerados pelo intenso fluxo de imigração europeia. A argentinidad, defendida por Evar Méndez, diretor da revista, foi definida na cidade, porque ela congregava a "síntese do país", isto é, da cultura nacional e da modernidade. A proposta de Martín Fierro era agir contra o nacionalismo dos intelectuais do Centenário, num momento em que o crescimento expressivo da economia e dos distintos extratos sociais urbanos possibilitavam acentuar os conflitos de interesses entre as elites oligárquicas e a burguesia e as suas formas de representação simbólicas.

Xul Solar, membro ativo do grupo e colaborador da revista Martín Fierro, concebia a cidade como espaço da modernidade ao representar os novos modos de vida social nas suas pinturas, as quais eram povoadas de arranha-céus, aviões e máquinas imaginárias. A sua cidade configurou-se pela presença da multidão e das bandeiras de distintas nacionalidades que revelavam o cosmopolitismo, porém sem deixar de conectá-la com a sua imaginação mística ao inserir símbolos de diferentes convicções. $\mathrm{O}$ artista era sensível às novas tecnologias e às máquinas modernas, assim como à nova arquitetura dos grandes centros urbanos. As suas cidades, geralmente, não tinham passado, mas apenas presente e projeções futuras, fenômeno que o diferenciava do pensamento de seu amigo, Jorge Luis Borges, apesar da grande afinidade intelectual existente entre eles. Borges, depois de muitos anos distante de Buenos Aires, começou a desenvolver um olhar nostálgico sobre cidade e seus arrabaldes. Ele construiu um cenário urbano preso aos antigos bairros, onde os vestígios do meio rural não eram bem demarcados. A cidade foi focalizada por um olhar retrospectivo, circunscrito à memória hispano-criollo (SARLO, 2003, p. 34-38). Paralelas às representações simbólicas de Xul, que mesclavam cosmopolitismo com o moderno e o nacional, outros escritores criaram novas poéticas tendo por base a cidade, porém dirigidas aos avanços científicos, à mecanização do mundo contemporâneo e ao devir de Buenos Aires. Esses fenômenos exerceram o fascínio, por exemplo, em Oliverio Girondo e Roberto Arlt.

O espaço urbano constituía-se no locus de constantes transformações, num ritmo muito acelerado, que estimulava os artistas às novas percepções e experimentações poéticas. Foi nesse espaço em ebulição que a crítica de arte de Martín Fierro e de outros periódicos de vanguarda exerceu a função de analisar a modernização de Buenos Aires e de informar o público sobre as inovações em curso na Europa e seus propósitos. Assim, ela informava e formava a sua opinião, bem 
como preparava a recepção da nova plástica em voga no exterior e no país. Para tal, eram incorporadas ao texto as fotografias das cidades, da arquitetura racional, de máquinas e das novas tecnologias, além das reproduções de obras de arte modernas europeias. Segundo Evar Méndez, a carência de informações era tão grave, que condicionou os editores da revista a reproduzirem pinturas de Georges Seurat, André Lhote, Picasso, Rousseau, Chagall, Vlaminck, Marie Blanchard, Van Dongen, Max Ernst, Paul Gauguin e dos novos artistas argentinos (ALCALÁ; SCHWARTZ, 1992, p. 193).

Além da preocupação educativa, a direção da revista planejou ainda a intervenção do Estado para estimular o desenvolvimento artístico do país (SARLO, 1983, p. 141). O grupo de Martín Fierro propôs também um programa para transformar o circuito tradicional de consagração do artista e criar outras estratégias de acesso pelos jovens, através de concursos e premiações. A revista apoiou os artistas que foram estudar na Europa, tais como: Emilio Pettoruti, Hector Basaldúa, Aquiles Badi, Horacio Butler, Alfredo Bigatti, etc. Eles absorveram os aspectos construtivos da nova arte, nos quais o desenho ordenado exercia o controle da expressão subjetiva. A noção de construção dominava os discursos estéticos e políticos depois da primeira guerra, como mecanismo para o estabelecimento da ordem depois de um momento de caos. Esta noção estava presente também no Ultraísmo e nos discursos da crítica de arte.

Alfredo Guttero, preocupado com o estabelecimento de instituição para veicular a arte moderna, criou o Nuevo Salón (1929), que foi realizado apenas três anos consecutivos. Além dessa iniciativa, outros artistas fundaram o Taller Libre de Arte Contemporânea para propagar as concepções modernas através do ensino ${ }^{28}$.

A revista Proa (1922-23) reapareceu em 1924, quando sob nova direção, no editorial esclareceu que seu o projeto moderno não seria mais de ruptura, mas que iria aderir ao princípio de construção perseguido por uma das vertentes do Ultraísmo. Os dirigentes ${ }^{29}$ comungaram $^{-}$ suas ideias com as de Ortega y Gasset, em La deshumanización del arte (1925, p. 52), em que o escritor colocou em xeque a pluralidade dos movimentos de vanguarda, divergentes entre si, o abandono das

\footnotetext{
${ }^{28}$ Participaram do Taller Libre: Alfredo Gutero, Raquel Forner, Domingos Neira e Alfredo Bigatti.

${ }^{29}$ A direção da revista era composta por: Jorge L. Borges, Brandán Caraffa, Pablo Rojas Paz e Ricardo Güiraldes. Outras revistas destacaram-se, tais como: Inicial (1923-27) de teor socialista, em Buenos Aires, e Valoraciones (1923-1928) em La Plata. Inicial (1923-2). A primeira projetou a reforma da universidade.
} 
representações do mundo aparente e de seu sentido humano ${ }^{30}$. O grupo projetou ainda a afirmação da arte argentina nos centros internacionais, a partir da divulgação da revista nas principais cidades europeias e latino-americanas, e do convite a escritores, artistas, arquitetos e críticos de arte estrangeiros para colaborarem com textos e fotografias de suas obras. Entretanto, o desejo de consagração internacional deveria ser concretizado sem deixar de lado as especificidades culturais da arte de seu país, como meio de marcar a distinção.

Diante da modernização portenha e da imigração, Borges, nos livros Fervor de Buenos Aires (1923), Luna enfrente (1925) e Cuaderno San Martín (1929), abandonou o Ultraísmo em prol da memória portenha e considerou a fundação mítica de Buenos Aires, o antigo plano da cidade e de seus bairros e arrabaldes afastados do centro moderno, onde os vestígios do campo ainda estavam presentes, suas moradias e seus costumes (SARLO, 2003, p. 34-38; MICELI, 2012, p. 98). O centro da cidade era o espaço dos estrangeiros, onde não se encontrava o criollo autêntico, o porto se constituía no espaço universal e os arrabaldes dos criollos, localizados na periferia, eram identificados pelo escritor como espaço marginal, motivo de sua nostalgia e de sua percepção de futuro (LOUIS, 1997, p. 389).

Os livros de Borges repercutiram na revista Martín Fierro por seu olhar sensível, inovador e humano, em que conjugou o passado e o futuro em contraposição aos discursos teóricos de Lugones (MARECHAL, 1925, p. 190; LANGE, 1927, p. 332). Em distintos momentos, Borges, Rojas e Lugones revisaram a história cultural argentina e revelaram algumas ideias semelhantes, como aquela relativa à política liberal estabelecida após a queda de Rosas que teria motivado o enfraquecimento das tradições criollas $^{31}$.

Xul Solar juntamente com os membros do grupo Martín Fierro, batalhou pela renovação artística, divulgou as suas ideias por meio de manifesto, obras e textos nas revistas e exposições. Logo após a sua chegada a Buenos Aires, Xul redigiu um texto, no mencionado

\footnotetext{
${ }^{30}$ Norah Borges e André Lhote foram destacados em Proa, dentre outros artistas, como emblemáticos da acepção de arte moderna. Lhote foi na França o maior difusor do Retour à l'Ordre, isto é, do retorno às raízes nacionais, em artigos, livros e aulas ministradas na sua academia. Ele formou inúmeros artistas argentinos e latino-americanos.

${ }^{31}$ Em Inquisiciones (1925), Borges analisou o problema do enfraquecimento das práticas culturais criollas, e procurou solucionar com a inovação da linguagem e a retomada da literatura de tradição criolla. No entanto, ele não deixou de dialogar com as poéticas hispânica e germânica contemporâneas e com sua formação anglo-saxônica. Ele concedeu ao passado a função de pensar o seu significado e de projetar o porvir em busca de coesão social.
} 
periódico $^{32}$ (SOLAR, 1924, p. 1-7), sobre a mostra de Emilio Pettoruti na galeria Witcomb (1868-1971), em que enfatizou a modernidade da obra do colega e sua independência espiritual (SOLAR, 1924, p. 73-74). Posteriormente, ele expôs as suas aquarelas no I Salón Libre de Buenos Aires, sendo as mesmas e as obras de Pettoruti pouco compreendidas e aceitas pela crítica de arte e pelo público ${ }^{33}$. Nesse momento, o público argentino, em geral, desconhecia as práticas artísticas das vanguardas europeias e resistia às inovações plásticas.

Xul Solar, apesar de compor o grupo de Martín Fierro, como membro ativo, afastou-se parcialmente da proposta dominante de arte ao mesclar a modernidade estética com sua imaginação mística e lírica de mundo. Na pintura, ele retomou os símbolos arcaicos pré-colombianos, esotéricos e nacionais, como as bandeiras em detrimento do gaúcho e da paisagem argentina, que eram distribuídos, lado a lado, com os signos da modernidade europeia. A conciliação estética entre signos autóctones e modernos, nacionais e universais, demonstrava, de um lado, a noção de mescla cultural e, de outro, a sua preocupação com a problemática da unidade americana, que foi objeto de debate pelos intelectuais, nos anos de 1910 e 20, inclusive pelos de Martín Fierro. Nos anos de 1920, a obra de Xul gerou tanto a rejeição, como a apatia por parte do público e da crítica, que não demonstraram admirá-la ou compreendê-la profundamente. Verifica-se a quase inexistência de textos de membros do grupo Martín Fierro na revista e em outros periódicos sobre a sua obra.

Esse fenômeno explica-se, em parte, pelo fato de que Ernesto Vautier e Alberto Prebisch, arquitetos e críticos de arte em Martín Fierro, demonstravam nos seus artigos concepções de arte distintas de Xul. Para eles, o gosto pela beleza da máquina provocou nos artistas inesperadas percepções do objeto e o desejo de apropriação dos seus caracteres plásticos e de suas formas puras, para a elaboração de uma estética condicionada ao tecnicismo moderno ${ }^{34}$ (PREBISCH, 1926, p. 219-221). Eles procuravam defender a conciliação dos

${ }^{32} \mathrm{O}$ texto foi ilustrado por pinturas de Pettoruti produzidas na Itália e o autor enfatizou que as mesmas evidenciavam os germes da arte do futuro. As pinturas de Pettoruti apresentavam inicialmente formas cubofuturistas, mas aos poucos tornaram-se construídas e ordenadas.

${ }^{33}$ Xul praticou uma pintura extremamente pessoal que o levou a não se ligar aos grupos de artistas que estudaram na França e na Itália, cujas obras se encontravam mais vinculadas às tendências de controle da modernidade desses países, como o Retour à l'Ordre e o Novecento. Esses artistas foram mais rapidamente consagrados na Argentina, já que conciliavam os signos nacionais, modernos e tradicionais sem produzirem rupturas com o gosto predominante.

${ }^{34}$ Os dois críticos de arte foram os primeiros a difundirem as ideias de Le Corbusier, apresentadas na revista L'Esprit Nouveau e da Bauhaus, na Argentina. 
domínios criativo, intelectual e científico e o controle da individualidade na arte para construir a moderna sociedade e seus sistemas simbólicos de representação de modo ordenados e controlados pela razão.

Vautier e Prebisch sustentavam que a noção de "beleza foi sempre o resultado de um processo construtivo de analógica arquiteturação de formas criadas pelo espírito". Para eles, "o Partenon clássico e o automóvel contemporâneo respondiam intimamente a um mesmo processo criativo" (VAUTIER; PREBISCH, 1925, p. 141). A composição da arte, cujas formas deveriam ser construídas pela geometria, também estava presente na poesia de Martín Fierro. "Construímos, de acordo com as necessidades arquitetônicas de um poema" (BORGES, 1980, p. 19). Tanto no manifesto deste periódico, como nos textos da crítica de arte observa-se a exaltação à máquina e à tecnologia, como signos da modernidade, que melhor revelavam o progresso e o anacronismo da arte oficial argentina.

A presença de textos de vários críticos de arte - argentinos e europeus - e de artigos sobre a arte europeia em Martín Fierro, observa-se que os mesmos focalizavam, sobretudo, as obras de artistas italianos e franceses modernos. A arte alemã foi praticamente ignorada, exceto por Sandro Piantanida, crítico de arte de origem italiana. Ele em Descubrimiento del Cubismo emitiu o seu juízo sobre a arte alemã ao afirmar que a mesma havia retrocedido pelo fato dos artistas inspirarem-se "naturalmente no misticismo" e na sua imaginação, que a conduziram à exaltação "do fantástico" e do "grotesco religioso". Esse crítico destacou ainda que essa expressão artística se encontrava afastada do espírito latino e justificou ao analisar a situação da arte italiana contemporânea: "Em meio ao caos (...) a Itália salvou o tradicional espírito clássico (...) inerente à natureza do artista", a sua visão de mundo e o "equilíbrio entre a faculdade de comover-se e a faculdade de (...) expressar" (PIANTANIDA, 1925, p. 94).

O seu pensamento também se apoiava nas concepções de arte moderna, atreladas às tradições clássicas e ao controle da subjetividade, próprias ao Novecento, após as ações de ruptura do Futurismo. Para ele, a nova construção formal foi o meio pelo qual os artistas encontraram para ordenar as sociedades europeias após a guerra e a um período de crise e anarquia. Neste sentido ele salientou o Cubismo do após guerra como outra solução, por sua objetividade e construção formal ordenada (PIANTANIDA, 1925, p. 94). 
Xul fez várias exposições ${ }^{35}$, mas Prebisch ao comentar a mostra realizada nos Amigos del Arte, quando da visita de Filipo Marinetti a Buenos Aires, em 1926, fez apenas a menção de que a sua "arte (era) misteriosa e simbólica" (PREBISCH, 1926, p. 219-221). Na mesma revista, foi apresentada na capa uma pintura de Xul, "Milícia", cujas formas geométricas construídas, em movimento, dominavam e nas páginas internas apareceram ainda "Angel" e "Escenario", que seguiam a mesma planimetria da primeira, porém mais vinculadas às fantasias do artista. As suas obras não suscitaram o maior interesse dos críticos de arte, talvez motivados por concepções estéticas distintas e por suas estranhezas diante do fantástico.

Os críticos de arte estrangeiros e de grande projeção na Europa, como Elef Teriade, Camille Mauclair, André Lhote, dentre outros, remetiam matérias para Martín Fierro, em que analisavam as obras de artistas franceses, cujas formas eram construídas e ordenadas, segundo as acepções do Retour à l'Ordre. O argentino, Julio Payró ${ }^{36}$, enviava da Bélgica artigos que valorizavam também as mesmas questões relativas à modernidade ordenada pela tradição.

Oliverio Girondo, diretor do periódico, escreveu posteriormente que se, por um lado, havia a multiplicidade de expressões literárias em Martín Fierro; por outro, em artes plásticas e arquitetura havia uma "nítida firmeza de (...) orientação", apoiada pelas ideias de Le Corbusier em L'Esprit Nouveau (1920-25) (GIRONDO, 1949, p. 47, 50). Este fenômeno era decorrente da presença de vários artistas e arquitetos argentinos na França, que entraram em contato com as

\footnotetext{
${ }^{35}$ Exposições realizadas en Buenos Aires e participações em salões: 1924, I Salón Libre; 1925, Salón de los Independientes; 1926, Exposición de Pintores Modernos em Amigos del Arte, Salón de los Independientes, Exposición em La Peña; 1927, Salón Florida; 1929, Exposición Xul Solar, em Amigos del Arte; 1930, Salón de Pintores y Escultores Modernos.

${ }^{36}$ Júlio Payró, crítico argentino que vivia em Bruxelas, colaborava com o jornal La Nación (192427) e a revista Nosotros (1927-28), com o fim de informar o público e de emitir conceitos a respeito da nova arte europeia. Em 1928, ele escreveu um "Ensayo sobre las tendencias de las artes plásticas modernos", no qual afirmou que "o artista de hoje não nega a arte do passado e não se obriga a criar algo novo". Porém, Payró acrescentou que a "escola moderna se opunha violentamente ao impressionismo" ao se orientar pelas "formas puras", afastadas da realidade visível. A proposta defendida pelo crítico era resultante da síntese produzida por certos movimentos artísticos com a tradição clássica e as pesquisas de Cézanne, conhecidas na França como o Retour à l'Ordre. O desenho, a forma geométrica pura e a recuperação do beau métier foram os mecanismos pelos quais os artistas franceses procuraram restabelecer a ordem. Nesse momento em que dominavam os nacionalismos exacerbados, os discursos estéticos na França, Alemanha e Itália baseavam-se na recuperação do passado, no controle da modernidade e da expressão subjetiva. Nessa linha de pensamento seguia também o crítico, Elef Teriade, que escrevia para os periódicos franceses L'Intransigeant e Cahiers d'Art. Colaborava ainda com o jornal La Nación, a partir da segunda metade da década de 1920, e verifica-se que seus textos se fundamentavam sob conviç̧ões similares.
} 
noções da arquitetura racionalista de Le Corbusier, cujos princípios se fundamentavam na arquitetura clássica, na funcionalidade, nas novas técnicas construtivas e no controle da expressão artística. L'Esprit Nouveau compunha o movimento de retorno às tradições, porém atrelado à uma modernidade mais conservadora dos valores eternos da arte.

Martín Fierro veiculou juntamente o Ultraísmo e o Creacionismo, com o Retour à l'Ordre, o Novecento e textos da revista L'Esprit Nouveau, deixando de lado o Surrealismo, as Abstrações e os Construtivismos. Apresentou o Futurismo apenas quando Marinetti visitou Buenos Aires, mas seus colaboradores não aderiram ao mesmo. Nas artes não houve, em geral, manifestações de adesão ao Dadaísmo, nem ao Expressionismo, movimento com o qual Xul em parte se identificava ${ }^{37}$.

O próprio Xul Solar, quando em 1924, analisou a pintura de Pettoruti e salientou "uma tendência bem definida até a simplicidade de meios, a arquitetura clara e sólida, até a pura plástica que conserva, acentua a significação abstrata de linhas, massa e cor (...)" (SOLAR, 1924, p. 63-67). Observa-se que ele também destacou alguns dos valores próprios daquele momento de retração das vanguardas, fundados nas noções de construção e ordem, apesar da obra de Pettoruti não se restringir às mesmas.

Muitos dos artistas que estudaram na Europa, nos anos de 1920, ao retornarem a Buenos Aires procuraram propagar as inovações estéticas, para formar o olhar do público, e fundar novas instâncias de legitimação, porém sem produzir rupturas. Pettorutti de 1924 a 1930 escreveu no jornal Critica, onde apresentou a arte italiana do Futurismo ao Novecento, da vanguarda ao movimento nacionalista liderado por Margherita Sarfatti e consagrado pelo fascismo ${ }^{38}$.

As estratégias direcionadas à renovação praticadas pela nova crítica de arte e pelos jovens artistas revelavam noções de modernidade moderadas, fenômeno que não diferia muito do velho continente, onde os artistas abandonaram o caráter revolucionário, que antecedeu a primeira guerra mundial. Durante e após o conflito, quando os ideais liberais começaram a ser repensados e os nacionalismos se acentuaram, os artistas modernos procuraram exercer uma função social mais efetiva e controlaram o processo de mudança. Eles assumiram uma postura dirigida

\footnotetext{
${ }^{37}$ Antonio Berni manteve contato com André Breton, mas a sua pintura e a de Lino Spilimbergo, nos anos 20, encontravam-se mais próximas à metafísica de De Chirico, condicionadas às longas perspectivas, à cristalização do tempo, ao silêncio e ao enigma.

${ }^{38}$ Sarfatti trouxe uma exposição do Novecento a Buenos Aires (1930) e incluiu alguns artistas argentinos.
} 
à coletividade em detrimento do individualismo, da originalidade e do caráter hermético das obras das vanguardas e buscaram a aproximação maior com o público. Ao abandonar os discursos e gestos de ruptura com a tradição, muitos artistas europeus retomaram as representações simbólicas nacionais e/ou revisaram as práticas dos mestres do passado para criação de novas poéticas.

Na década de 1920 em Buenos Aires, os artistas que se consideravam modernos, os militantes de esquerda como aqueles mais conservadores batalharam por fins nacionalistas e resistiram às propostas revolucionárias. A forma pura, reivindicada pelos intelectuais ligados à revista Martín Fierro, apresentou resultados restritos, na medida em que estava atrelada, em parte, à tradição figurativa e à construção de nova identidade nacional. Apesar das articulações efetuadas pelos militantes da modernidade estética e da preparação do público, as obras não foram sempre muito bem recebidas.

Os periódicos de vanguarda argentinos, como por exemplo, Martín Fierro, Prisma (1921-22) ${ }^{39}$ e Proa (1924-5) ${ }^{40}$, além de propagarem a nova arte exerceram a função de tornar conhecida a jovem elite intelectual, suas ideias e seus projetos de nação moderna. No entanto, as tensões no campo persistiram sobretudo no domínio literário erudito, no qual os escritores produziam textos críticos em relação aos folhetins, jornais, revistas e livros populares, mas sem deixar de publicar em periódicos de esquerda, direcionados à grande massa da população. Dentre eles destacou-se nos anos de 1920 Jorge L. Borges, que colaborava com os grandes jornais, como Critica (1913) e El Mundo (1928), motivado pela projeção da reforma social que, para ele, deveria partir da educação das massas (SARLO, 2003, p. 36-37). As estratégias traçadas em relação à educação do público em geral, somadas ao crescimento significativo de periódicos e de editoras possibilitaram a consolidação de um circuito de leitores e a democratização cultural (SARLO, 1997, p. 206). Xul ao mesmo tempo que concedia entrevistas ao jornal La Nación também divulgava o seu pensamento e obra para os meios de comunicação populares, como El Hogar e Almanaque de la Mujer, dentre outros ${ }^{41}$ (ARTUNDO, 2005, p. 59-95).

\footnotetext{
${ }^{39}$ Revista que contava na redação Eduardo Lanuza, Francisco Piñero, Guillermo de Torres e Guillermo Juan Borges, J. L. Borges. Foram publicados apenas dois números.

${ }^{40} \mathrm{Na}$ revista Proa a meta da direção era mostrar como a poesia, a pintura e a música tinham correspondências entre si e os intercâmbios promovidos na modernidade. Nela os desenhos, as pinturas e vinhetas exerciam o papel de difundir a nova visualidade, a partir de formas esquemáticas. As gravuras de Norah Borges de caráter inicial expressionista se transformaram independente dos textos com os quais elas estavam vinculadas, num discurso visual autônomo.

${ }^{41}$ Ela destaca as entrevistas dadas por Xul nas décadas de 1920 e 1930.
} 
Os artistas, de origem operária, criaram instituições de circulação e legitimação, como foi a fundação do Salón de Artistas Independientes, como instância livre de dogmatismos e de critérios rigorosos, pois tinham o objetivo de superar as antigas limitações das instituições oficiais do Estado. Com isto, contribuíram para legitimar a nova geração de artistas e divulgar as suas concepções estéticas. ${ }^{42} \mathrm{O}$ periódico mensal Acción de Arte (1920-21), dirigido pelo crítico de arte Atalaya desempenhou papel importante na criação do salão e da Asociación Independiente de Artistas Plásticos e na formação de público. O crítico de arte atuou ainda no Suplemento Semanal (1922-26) de La Protesta e na La Campana de Palos (1925-6), nos quais divulgava e analisava as obras dos artistas expostas nos salões (LAFLEUR, 1967, p. 109-114).

A expansão do nacionalismo também se processou de forma acentuada na esfera cultural popular, através do criollismo, que resgatou os antigos costumes do campo, valorizando-os em contraposição à cidade e aos novos comportamentos sociais. Nos folhetins, o espaço urbano passou a ser rotulado como caótico e o cosmopolitismo foi condenado pela instabilidade que produzia na sociedade. Assim, surgiram inúmeros centros de tradições populares, que aprofundaram as tensões com a vertente de intelectuais modernos que procurava retomar as representações simbólicas do país e re-elaborar a memória coletiva, tendo como cenário a cidade (PENHOS, 1999, p. 113).

A concepção nacionalista da crítica de arte, do Salão Nacional, dos artistas e das instituições de ensino condicionou à preservação, pelas instâncias oficiais, de práticas artísticas mais conservadoras. Com isto, o conflito se estabeleceu no interior do campo de arte entre os projetos renovadores e aqueles pautados na tradição; bem como entre os modernos e os grupos de artistas de esquerda, como, por exemplo, Amigos Del Pueblo e Boedo. ${ }^{43}$ Estes dois grupos atuaram com o objetivo de utilizar a arte como mecanismo de militância política, ao identificarse com o proletariado nacional e ao não aceitarem as experiências formais, oriundas das vanguardas europeias, dirigidas, segundo eles, apenas aos aspectos plásticos. Boedo e Amigos Del Pueblo produziram obras de fácil compreensão, com o objetivo de salientar ao público suas lutas pelas causas sociais. Assim, emergiu outro pólo de atrito, que

\footnotetext{
${ }^{42}$ Foram ainda promovidos: em 1926, o Salón de Artistas Modernos, por ocasião da visita de Marinetti a Buenos Aires; em 1928, o Salón de Artistas Argentinos, em La Peña; e de 1929 a 1932 o Nuevo Salón.

${ }^{43}$ Boedo surgiu a partir da revista Pensadores, criada em 1922. Muitos dos seus componentes eram membros do Partido Comunista e defensores do realismo social.
} 
gerou debates em torno das questões a respeito da arte pela arte e/ou arte com fim social. No entanto, deve-se destacar que o objetivo em comum desses artistas de posições diferentes era a arte nacional, porém oriunda de distintas vertentes ideológicas e de projetos próprios.

A militância política dos artistas demonstrou a fragilidade da relativa autonomia da prática artística e, ao mesmo tempo, a concepção de arte dirigida à transformação social os obrigou a manterem formas de representação narrativas, vinculadas ao mundo aparente para serem rapidamente entendidas pelo público.

Nos anos de 1920, as artes portenhas atrelavam-se ao mesmo tempo às formas de representação visual dirigidas à denúncia social, produzidas por militantes de esquerda; às tradições nacionais rurais e urbanas, sustentadas por intelectuais e instituições conservadoras, como por aqueles artistas que se propunham como modernos; e à arte orientada às questões internas, de ordem formal. Entre os modernos haviam divergências de concepções motivadas pelas relações que mantinham com distintos movimentos de arte, que muitas vezes se contrapunham entre si.

\section{Considerações finais}

O campo artístico estava dividido entre artistas condicionados à memória nacional rural (Fader e Quiróz); aqueles que buscaram a renovação plástica, mas se mantiveram presos às disciplinas da retomada da ordem e aos signos nacionais (Butler, Basaldúa); os militantes de esquerda (Antonio Berni e o Grupo Boedo) que conservaram a figuração realista; e os artistas relativamente mais formalistas (Xul, Pettorutti e Juan del Prete) que enfrentaram resistências institucionais. A pluralidade de concepções possibilitou intensas disputas e embates no interior do campo de arte e evidenciou que a noção de "campos de forças" de Bourdieu é pertinente para se analisar os conflitos e as lutas internas do campo que não são meramente simbólicos, isentos de neutralidade, mas que se constituem em lutas de poder. Os embates não se limitam ao âmbito da tradição e modernidade, mas são de ordem política.

As condições favoráveis da economia argentina e das elites sociais, juntamente, com a formação de gosto do público efetuada por artistas, críticos de arte e exposições permitiram a constituição em Buenos Aires de colecionadores e o início de um mercado de arte desde 1880. (BALDASARE, 2006, p. 13-14). Nesse momento, já haviam galerias 
de arte e ao longo dos anos de 1920, outras surgiram e possibilitaram a expansão do mercado.

No campo intelectual, as práticas literárias modernas, apesar de se centrarem na cidade, também não revolucionaram como os escritores acreditavam e, em geral, continuaram condicionadas aos ideais nacionalistas sem romper plenamente com certos pressupostos dos intelectuais do Centenário, como se procurou mostrar ao longo deste artigo. Entretanto, a reforma educacional e a expressiva produção intelectual permitiram a constituição de forte mercado editorial.

As tensões no campo intelectual e de arte persistiram diante das distintas ideologias, dos projetos de nação e de cultura nacional, que culminaram com o golpe do general José Uriburu (1930) e com o estabelecimento da ditadura no país (1930-32). O campo intelectual e artístico sofreu interferências de instâncias políticas, a censura começou a vigorar e foi nomeado um interventor para a Universidade de Buenos Aires. O país passou por uma fase de expurgos e de consagração de intelectuais mais conservadores, que estreitaram laços com a Igreja, defenderam o moralismo cristão e simpatizaram com o fascismo italiano. Dentre os intelectuais argentinos que apoiaram o nacionalismo e a ditadura destacou-se Leopoldo Lugones, que estreitou as relações com os militares que prepararam o golpe e redigiu o manifesto com as premissas do projeto político de governo (BARBERO, DEVOTO, 1983, p. 145-148). Frente a esses acontecimentos, o campo intelectual e de arte perdeu a sua autonomia e Borges, Xul e outros artistas abandonaram as suas propostas relativas à identidade nacional e se direcionaram para a criação de novas poéticas, sendo que Xul enveredou num misticismo profundo.

\section{Referências}

ALCALÁ, May Lorenzo. La esquiva huella del Futurismo en el Rio de La Plata. Buenos Aires: Ambasciada d'Italia, Instituto Italiano di Cultura, Patricia Rizzo ed., 2009.

ALCALÁ, May Lorenzo; SCHWARTZ, J. Vanguardas argentinas anos 20. São Paulo: Iluminuras, 1992.

ARTUNDO, Patricia. Alejandro Xul Solar. Entrevistas, artículos y textos inéditos. Buenos Aires: Corregidor, 2005.

. Alfredo Guttero en Buenos Aires 1927-1932. In: Arte argentino del siglo XX. Buenos Aires: Fundación para la Investigación del Arte Argentino, 1997.

BALDASARE, M. I. Los dueños del arte. Coleccionismo y consumo cultural em Buenos Aires. Buenos Aires: Edhasa, 2006. 
BALDASARE, M. I.; DEVOTO, F. Los nacionalistas. (1910-1938). Buenos Aires: CEAL, 1983.

BOURDIEU, P. Coisas ditas. São Paulo: Brasiliense, 1990. . A economia das trocas simbólicas. São Paulo: Perspectiva, 1982.

BORGES, J. L. Proa facsimile. Buenos Aires: Biblioteca Nacional, v. 1, p. 3-8, 2011. BORGES, J. L. et al. Boedo y Florida. Buenos Aires: CEAL, 1980.

BURUCUA, J. E.; TELESCA, Ana M. El Impressionismo en la pintura argentina. Estudios e Investigaciones, Instituto de Historia de las Artes Julio E. Payró, Buenos Aires, UBA, n. 3, [s.d.].

D’ORS, Carlos. El Noucentisme. Presupuestos ideológicos y artísticos. Madri: Cátedra, 2000.

GIRONDO, O. El periodico Martín Fierro. Buenos Aires: 1949.

GUIDO, A. En defensa de Euríndia. El Círculo, Rosario out-inverno, 1924. In: GUTIERREZ VIÑUALES, Rodrigo. O Neo-Pré-Hispânico na arquitetura. Arquitextos, ano 4, p. 37, oct. 2003.

KERN, Maria Lúcia Bastos. Arte argentina. Tradição e modernidade. Porto Alegre: Edipucrs, 1996.

. Imagem em movimento. In: Anais do XXXIV Colóquio Brasileiro de História da Arte, Uberlândia, 2014.

LAFLEUR, Hector et al. Las revistas literárias argentinas. Buenos Aires: CEAL, 1962.

LANGE, Norah. Jorge Luis Borges pensado em algo. In: Martín Fierro, Buenos Aires, n. 40, abr. 1927.

LOPEZ ANAYA, Jorge. Arte argentino. Buenos Aires: Emecé, 2005.

LOUIS, Annick. Jorge Luis Borges: oeuvre et manoeuvres. Paris: L'Harmattan, 1997.

Manifesto Martín Fierro, Buenos Aires, n, 4, 15 mayo 1924.

MALHARRO Pintura y escultura. Exposición de Bellas Artes. Ideas, ano I, n. 2, 1903. In: BURUCUA, J. E.; TELESCA, Ana M. El Impressionismo en la pintura argentina. Estudios e Investigaciones, Instituto de Historia de las Artes Julio E. Payró, Buenos Aires, UBA, n. 3, [s.d.].

MARECHAL, Leopoldo. Luna enfrente, por Jorge Luis Borges. In: Martín Fierro, Buenos Aires, n. 26, p. 190, dic. 1925. (Facsimile).

. Adán de Buenosayres. Buenos Aires: Seix Barral, 2003.

Martín Fierro, Buenos Aires: Fondo Nacional de las Artes, 1995. (Facsimile).

MICELI, S. Vanguardas em retrocesso. São Paulo: Companhia das Letras, 2012.

MUÑOZ, Miguel A. Los artistas del pueblo. La vanguardía política de princípios de siglo en Buenos Aires. In: BULHÕES, M. A; KERN, M. L. Artes plásticas na América Latina contemporâneas. Porto Alegre: Editora da UFRGS, 1994.

. Manuel Galvez, crítico de arte. In: Caiana - Revista de História del Arte y Cultura Visual del Centro Argentino de Investigadores de Arte, CAIA, Buenos Aires, s.p., sept. 2012.

ORTEGA Y GASSET, José. La deshumanización del arte. Revista Ocidente, Madri, 1970. 
PÉREZ, Juan Pablo et al. Lecturas, problemas y discusiones en el arte argentino del último siglo. 1910-2010. Buenos Aires: Fondo Nacional de Artes, 2010.

PENHOS, Marta. Nativos em el salón. Artes plásticas e identidad en la primera mitad del siglo XX. In: PENHOS Y WECHSLER (Coord.). Tras los pasos de la norma. Buenos Aires: Jilguero, 1999.

PIANTANIDA, S. Descubrimiento del Cubismo. In: Martín Fierro, Buenos Aires, n. 14-15, p. 94, 24 enero 1925. (Facsimile).

PREBISCH, A. Marinetti en los Amigos del Arte. In: Martin Fierro, Buenos Aires, n. 30-31, p. 219-221, 8 julio 1926.

PULFER, Dario. In: ROJAS, R. La restauracción nacionalista. La Plata: Universitaria UNIPE, 2010.

ROMERO, Jose Luis. Las ideas en la Argentina del siglo XX. Buenos Aires: Biblioteca Actual, 1987.

SARLO, B. Vanguardia y criollismo: la aventura de Martín Fierro. In: ALTAMIRO, C.; SARLO, B. Ensayos argentinos. Buenos Aires: CEDEAL, 1983.

. Paisagens imaginárias. São Paulo: Edusp, 1997.

. Borges, un escritor en las orillas. Buenos Aires: Seix Barral, 2003.

SOLAR, X. Pettoruti. In: Martín Fierro, Buenos Aires, n. 27, p. 73-74, sept./oct. 1924. (Facsimile).

VAUTIER; PREBISCH. Fantasia y Calculo. In: Martín Fierro, Buenos Aires, n. 20, p. 141, julio 1925. (Facsimile).

WECHSLER, D. Algunas consideraciones acerca de la vanguardia en el campo de Buenos Aires. In: Estúdios de Investigaciones, Inst. de Teoria e Historia del Arte Julio Payró, Buenos Aires, UBA, n. 2, 1989a.

Salón de Bellas Artes, promotor de vocaciones nacionalistas (1920-1930). In: $\overline{\text { Estúdios }}$ de Investigaciones, Inst. de Teoria e Historia del Arte Julio Payró, Buenos Aires, UBA, n. 2, 1989 b. 